\title{
A numerical study on the cooling water system of an accelerated cooling machine
}

\author{
S. Oh, S. Yoon \& P. Lee \\ POSCO Research Laboratories, POSCO, South Korea
}

\begin{abstract}
Recently, in metallurgy processes, cooling water control is important for controlling the mechanical properties of material. Water cooling is one of the best techniques for a hot steel plate manufacturing process because it can use a high cooling performance of boiling. In this work we conducted a numerical study about water flow control with a cooling water control machine for steel plate making. We calculated the pipe network of the cooling water supply machine with two types of (previous and new type) cooling headers using FLOWMASTER. With a cooling header replacement, such as a cooling header change and the area of cooling nozzles, we achieved the increment of cooling water capacity and cooling performance.
\end{abstract}

Keywords: steel plate making, accelerated cooling machine, cooling water control.

\section{Introduction}

Steel plates are used in the making of oil and gas pipe, in the shipbuilding and pressure vessels, etc. Recently, the demand of high quality steel plates is rapidly increased due to growth of offshore plants. To make high quality steel plates, the cooling water control is important. Metallurgy processes use various heattreatment techniques for controlling the mechanical properties of material. Water cooling is one of the best techniques for a hot steel plate manufacturing process because it can use a high cooling performance of boiling [1]. The water cooling method is classified into spray cooling and nozzle (or slit) cooling. When compared with the nozzle cooling, the spray cooling achieves higher cooling efficiency in the same coolant flow rate condition [2], but it has a limitation in increasing the flow rate, which is a dominant parameter to achieve a maximum 
performance in a hot steel plate cooling condition [3]. Many studies [4, 5] were performed to get high efficiency in nozzle and slit cooling. Recently, Lee et al. [6] carried out experimental tests about hot plate cooled by an impingement liquid jet. They studied the effect of nozzle height and suggested a correlation between Froude number and nozzle height.

Most of the steel plate making companies has the accelerated cooling machine in order to produce high-quality steel plate. A high-quality steel plates referred to as thermo-mechanical controlled rolling (TMCP - Thermo-Mechanical Control Process). The MULPIC is one of the best in-line cooling system which is used if direct quenching (DQ) or accelerated cooling (ACC), and many steel plate making company is used MULPIC for making steel plate. The POSCO has introduced the MULPIC by 1988. And the past few decades, we took advantage of this facility for the production and sale of a variety high quality steel plate. However, we need the improvement about MULPIC due to the few problems such as the deterioration of equipment, step-up in cooling performance.

In this study we performed the numerical analysis about the pipe network of cooling water supply machine with two type (previous and new type) cooling header using FLOWMASTER.

\section{Numerical analysis}

Figure 1 shows the schematic of MULPIC machine in our plant. This machine is composed high density cooling zone, low density cooling zone and zone separation spray. This facility has 7 cooling zones which is called DQ A, DQ B, A, B, C, D, E. Each cooling zone has four cooling headers. One cooling header is composed of two headers which located on top and bottom. The detail is described by Robinson et al. [1].

Flow Diagram of Cooling System

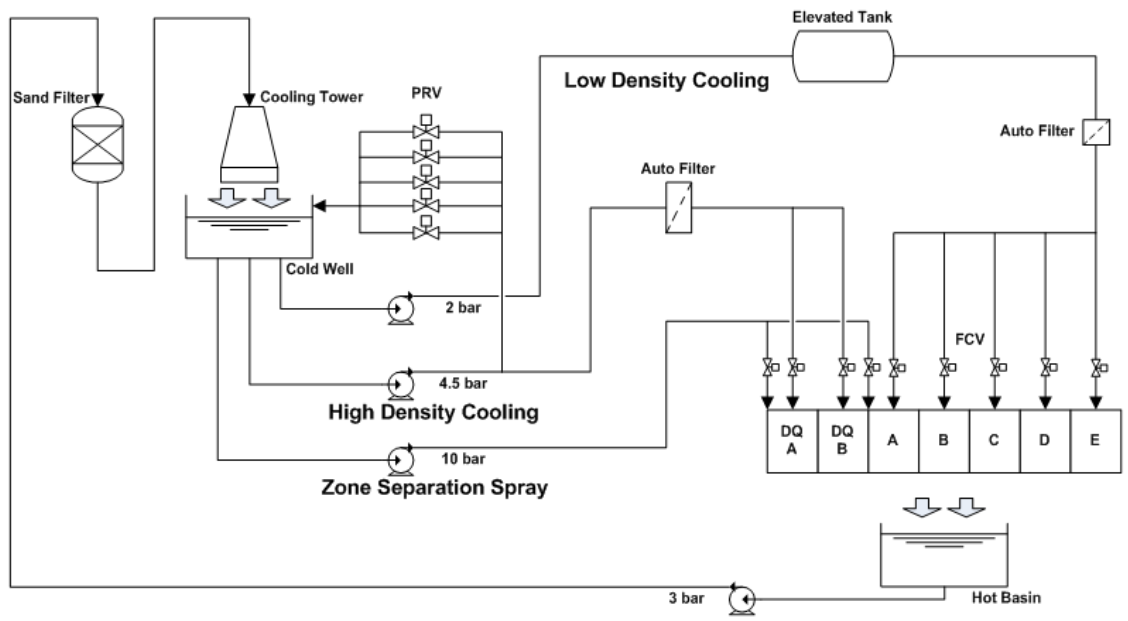

Figure 1: Schematic diagram of MULPIC. 
The purpose of this study is a simulation about cooling flow system which is included of the new cooling header with an existing cooling system. For this purpose, our study was carried out in the following.

First, we performed the development of new cooling header. The purpose of a new cooling header is the achievement high cooling performance. New cooling header was changed the header shape and nozzle diameter etc. The new and previous cooling header's flowrate vs. pressure curve is like figure 4.

Second, we performed the existing cooling system modelling. Figure 3 is a cooling system modelling using FLOWMASTER. FLOWMASTER is 1D analysis tool. 1D CFD tool is much faster than 3D CFD at a complex piping system. Therefore, FLOWMASTER is utilized a various application, such as aircraft, power generation design and general engineering. In this study, each component pressure loss coefficient is very important variables. We consider the correct pressure loss coefficient for an important part, such as control valve, cooling header, pipe roughness and auto back wash filter, etc. However, the 1D CFD tool lacks the accuracy when simulating complex cooling header. Therefore, we have carried out an experimental study about complex cooling header. And, pump performance curve and each component pressure loss coefficient were verified with the suppliers.

In this study, we conducted two cooling zone modifying, DQ A, DQ B. Therefore, the modelling is composed of DQ A, DQ B Bank, pump and PRV system. Each system is connected with a complex pipeline. The purpose of PRV system is a control of main piping line pressure [1]. This system is composed of five control valve and piping line. MULPIC has two cooling water supply functions referred to as ACC and DQ. ACC is a function which is supplied from elevated tank, and DQ function is supplied from direct pumping line. This study performed only DQ function simulation. Each DQ zone has four header sets. And 1 header set is composed of top and bottom header. Therefore, this study is calculated about total 16 headers.

Finally, we performed two type (steady state and transient type) simulations for describing cooling machine operating. For a transient simulation, a steady state simulation is essential. And this study was carried out the validation using a real cooling machine operating data. After validation, we calculated about a new cooling header with an existing cooling system.

For validation and transient simulation, we calculated two valve sequence scenarios. The scenarios are followed by figure 3. To achieve high quality steel plate, cooling water control is needed. Especially, the head and tail position of plate is more cooling than centre position of plate, therefore a cooling machine is controlled cooling water using control valve at the head and tail position of plate. This control function is called "Head-Tail Masking". And for controlling main pressure, the PRV scenario is shown in figure 3, too.

This paper presents about cooling water flowrate and cooling flow control performance with a new cooling header. 


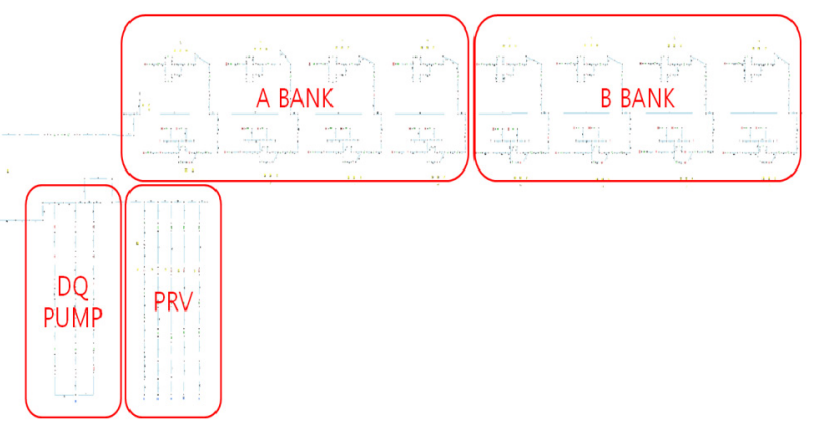

Figure 2: Modelling of MULPIC using FLOWMASTER.

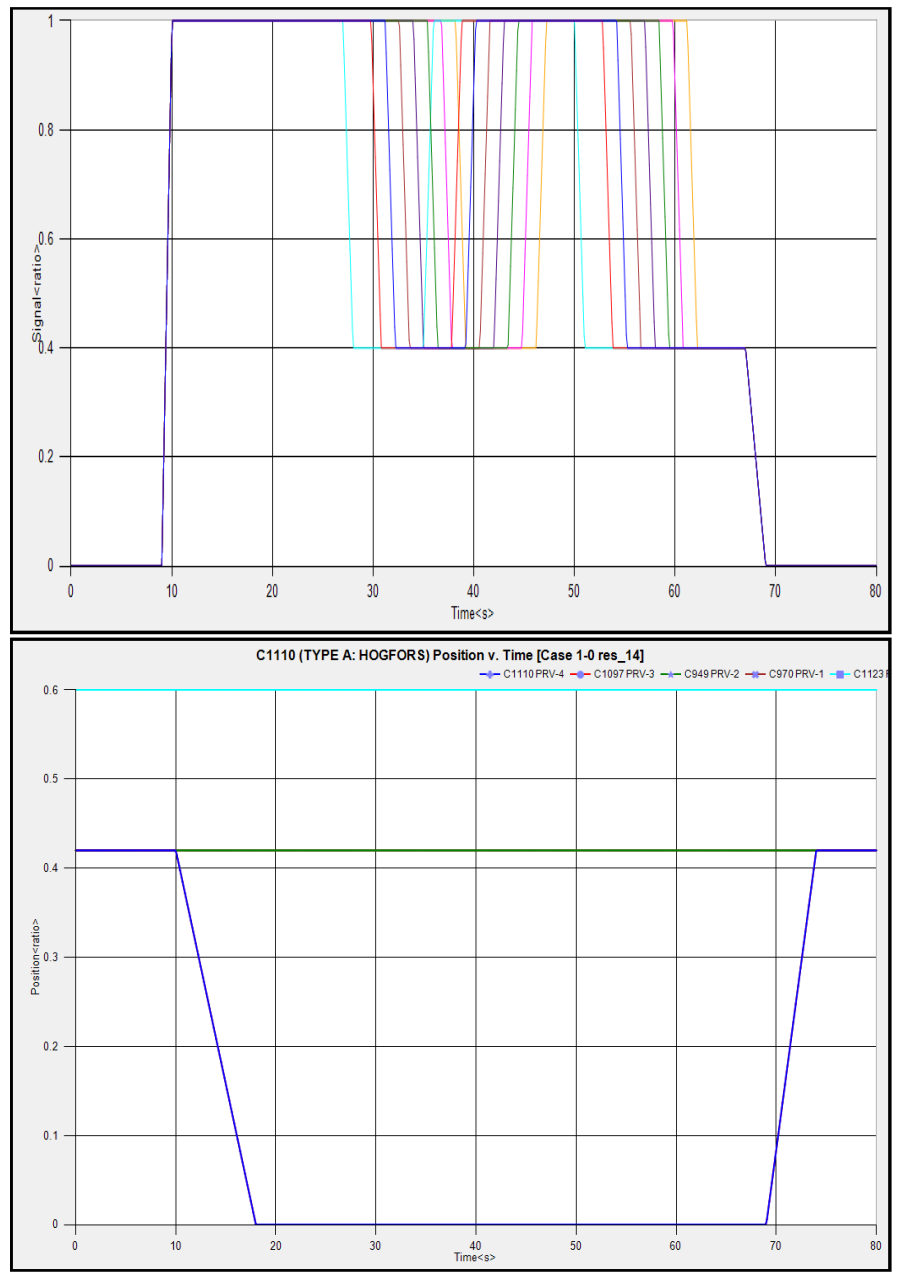

Figure 3: The valve opening scenarios with control valve and PRV. 


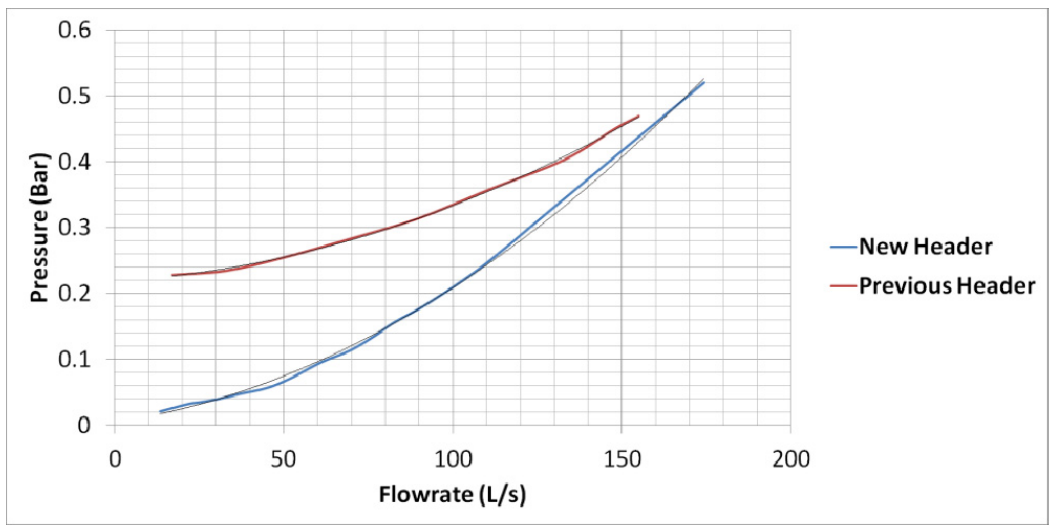

Figure 4: Comparison of the pressure vs. flowrate obtained new and old headers.

\section{Result and discussion}

\subsection{Validation}

For figures 5 and 6, 5 is cooling water and 6, the main pressure graph about the comparison CFD result with a real operating data. The predicted cooling water flowrate and main pressure curve is very similar to the real cooling machine operating data. This result presents that the modelling of this cooling machine performs relatively well.

When a control valve open and close time, the simulation result is steeper than the real operating result. It is caused by control valve operating times. It is little different with CFD case and real operating. In CFD case, each control valve operation is well described. This phenomenon cause is due to pressure scan interval. However, the predicted cooling water flowrate result is a relatively good agreement.

\subsection{Result of a new cooling header application}

Figure 7 shows the numerical result of a cooling water flowrate and main pressure about two type cooling headers. A new cooling header's pressure loss is smaller than an existing cooling header pressure loss. It is caused by a difference of a nozzle diameter and a nozzle number. The control valve opening rate is same in two results. However, the cooling water flowrate is increased at a new cooling header condition. This result is a same reason as mentioned. The maximum cooling water flowrate is increased about $29.6 \%$. And main pressure is decreased about $21.3 \%$. As mentioned, a new cooling header has a low pressure loss. Therefore, it can make a cooling water flowrate increment and a main pressure decrement at same condition. A main pressure is an important point for stable operating condition. This result presents that a new cooling header is able to decrease main pressure when the same cooling flowrate supplies. 

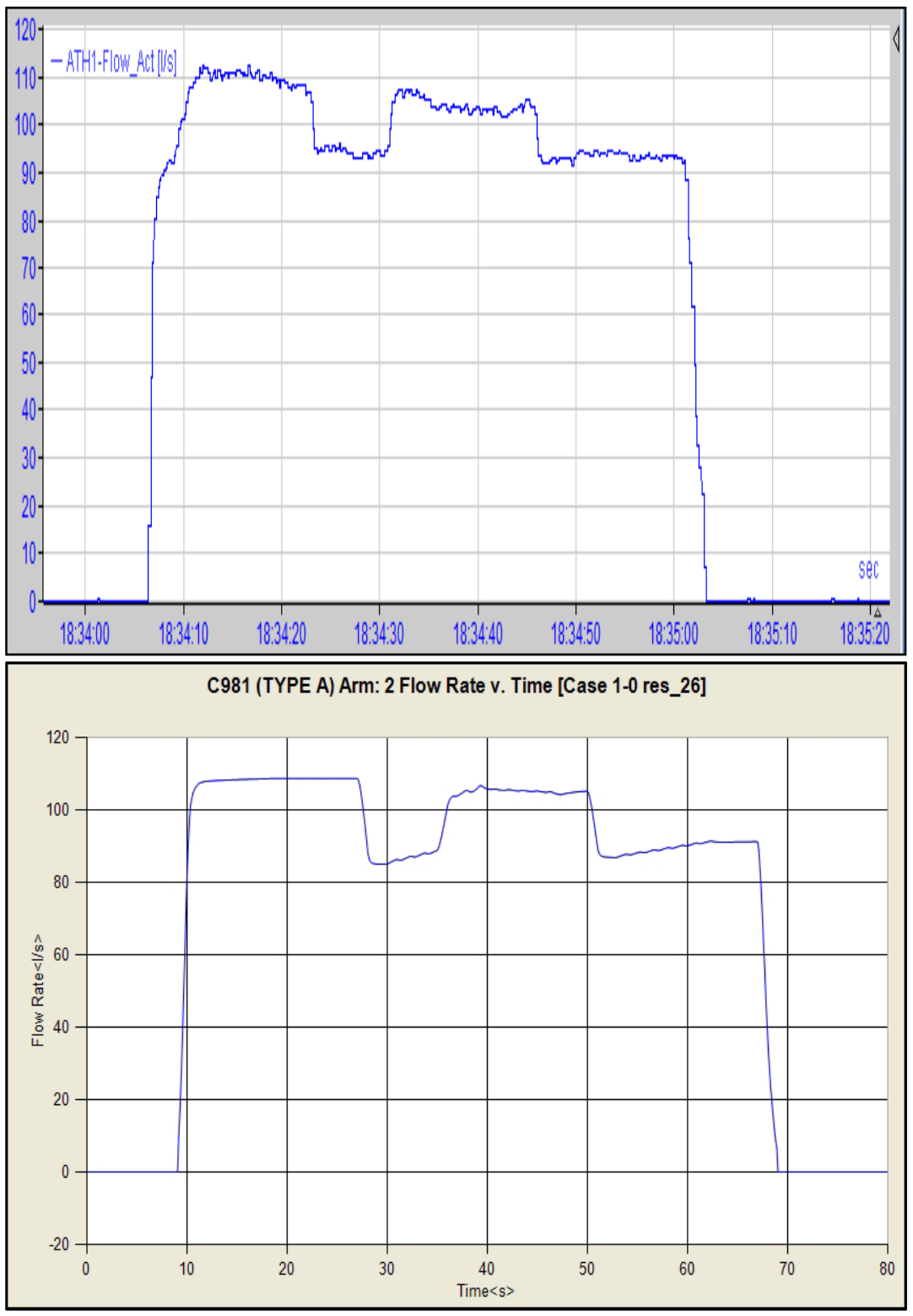

Figure 5: Comparison of the cooling water flowrate obtained CFD result and real operating data. 

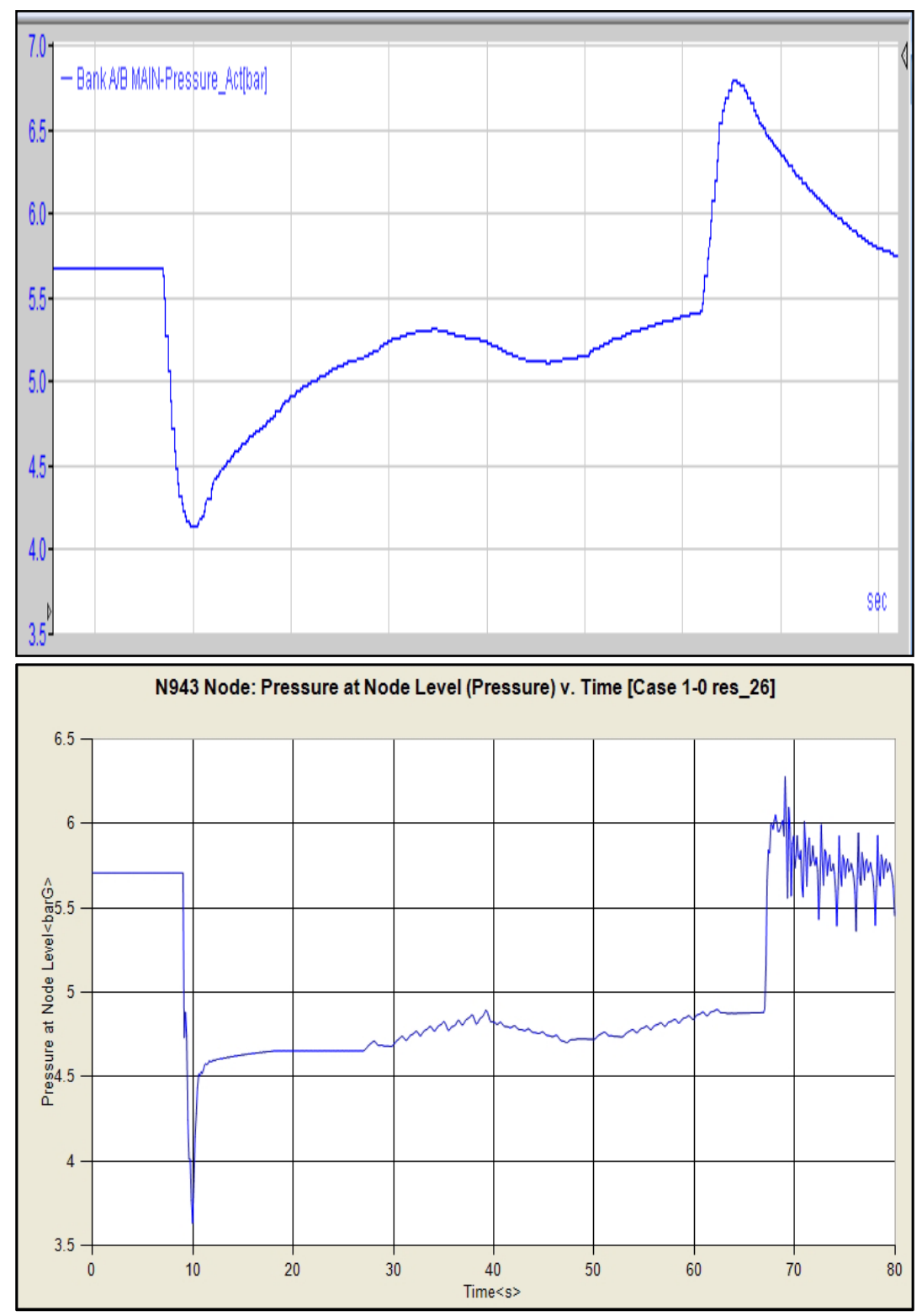

Figure 6: Comparison of the main pressure obtained CFD result and real operating data. 

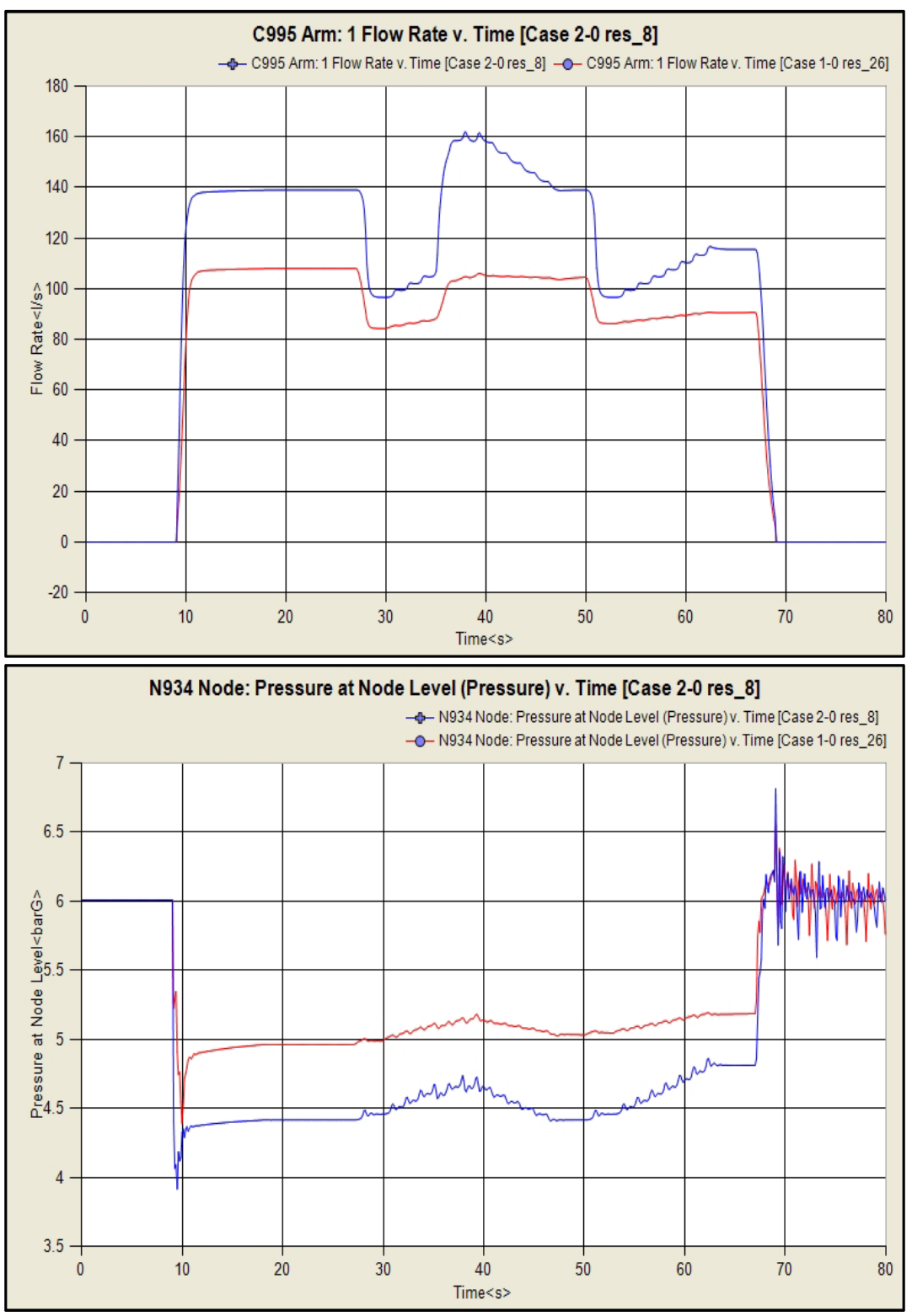

Figure 7: Comparison of the cooling water flowrate and the main pressure obtained CFD result with two type cooling header. 


\section{Conclusion}

A numerical study was conducted for cooling water supply system with two type cooling header. The following conclusions can be drawn from the present study.

1. Complete numerical simulation and validation was performed for cooling water supply machine. (MULPIC) The numerical simulation was based on 1D CFD tool. (FLOWMASTER).

2. Numerical simulation with two type cooling headers was carried out. New cooling header case has a cooling flowrate increment and a main pressure decrement. It is caused by pressure loss difference.

3. New cooling header is expected to make a better cooling performance and a more stable machine operation.

\section{References}

[1] I. S. Robinson, J. Lee and S. Samanta, Recent Application of the Mulpic Cooling Technology for Plate Mills, 2011 SEAISI Conference, 2011.

[2] T. Harri, T. Kondoh, T. Mori, K. Esaka, J. Wakita, Tetsu-ta-Hagane, 72, S1387, 1986.

[3] T. Ito, Y. Takata, M. Mousa, H. Yoshikai, Studies on the Water Cooling of Hot Surfaces, Memoirs of the Faculty of Engineering Kyushi University, Vol. 51, pp. 119-144, 1991.

[4] A. Otomo, K. Takatsuka, I. Takahashi, Y. Ohbanya, N. Akiyama, Y. Kobayashi, Tetsu-ta-Hagane, 73, 996, 1987.

[5] B. Whelan, P. Robinson, Nozzle geometry effects in liquid jet array Impingement, Applied Thermal Engineering, 29, pp. 2211-2221, 2009.

[6] P. Lee, H. Choi, S. Lee, The Effect of Nozzle Height on Cooling Heat Transfer from a Hot Steel Plate by an Impinging Liquid Jet, ISIJ International Journal, Vol. 44, pp. 704-709, 2004. 